\title{
Economics Across the School Curriculum-Benefits and Drawbacks of Some Related Approaches
}

\author{
Jahanbaksh Rahmani, Amir Toghyani Khorasgani* \\ Department of Educational Sciences, Isfahan (Khorasgan) Branch, Islamic Azad University, Isfahan, Iran \\ Email address: \\ a.toghyani@khuisf.ac.ir (A. T. Khorasgani) \\ To cite this article: \\ Jahanbaksh Rahmani, Amir Toghyani Khorasgani. Economics Across the School Curriculum-Benefits and Drawbacks of Some Related \\ Approaches. International Journal of Education, Culture and Society. Vol. 6, No. 1, 2021, pp. 9-14. doi: 10.11648/j.ijecs.20210601.12
}

Received: October 27, 2020; Accepted: November 24, 2020; Published: February 2, 2021

\begin{abstract}
Teaching economics as a distinct subject matter requires a curriculum rationale and curricular orientation no less than any other subject matter field. As with any social studies curriculum component, it is necessary to delineate the curriculum parameters of economics so as to justify and guide its teaching in the schools. This article aims to explore various approaches to developing and implementing economics curricula, weighs their benefits and drawbacks, and ends with a suggestion for blending the alternatives so as to optimize the benefits. Prior to the development of a curriculum rationale, however, the educator must ask a question seldom raised with the other social sciences: What kind of economics should be taught? Positive Versus Normative Economics The positive versus normative distinction in economics is particularly important in economic education.
\end{abstract}

Keywords: Curriculum, Normative Economics, Positive Economics, Infusion Approach, Synthetic Approach

\section{Introduction}

Trade deficits, stock market woes, inflation, and the energy crisis are examples of economic problems in almost every under development countries during the past three decades. However, it is unlikely that most citizens understand what created these kinds of problems or how leaders have tried to solve them. This lack of knowledge is a consequence of insufficient emphasis on economics in the general education of citizens [1]. Curriculum has been defined as "the complex network of what to teach and how to teach it" [2] and, variously, as "the study of 'what should constitute a world for learning and how to go about making this world"' [6]. Parkay and Hass (2000) stated that "The curriculum is all the experiences that individual learners have in a program of education whose purpose is to achieve broad goals and related specific objectives, which is planned in terms of a framework of theory and research, or past and present professional practice [10]. Formal definitions notwithstanding, curriculum is, in practice, the vehicle by which subject matter gets into the classroom and is taught to students. It is often said that "curriculum takes place when the teacher closes the classroom door." If this is the case, then unless a subject is taught by a trained and interested teacher, it is likely to be taught poorly or not at all. However, once the prerequisite of a trained teacher is met, one is left to decide the optimal method of assuring that the subject matter is included in the curriculum of a school district. Teaching economics as a distinct subject matter requires a curriculum rationale and curricular orientation no less than any other subject matter field. As with any social studies curriculum component, it is necessary to delineate the curriculum parameters of economics so as to justify and guide its teaching in the schools. The key goal is to formulate educational experiences that develop in students the ability and desire to continue self-directed learning over a lifetime. In other words, learn how to learn during lifetime and how to update their knowledge in the best way [1].

Fundamentally, human beings are eager to better their lives. If this is so then, we must ask ourselves, 'how do people accomplish good changes to better their lives?' It would be impossible to consider development without considering the economic benefits that provide us with a more comfortable and convenient life. Development may be a response to the economic needs of individuals in society. However, no one can simply focus on a single dimension of development because development is about the transformation of the economic, social, and cultural spheres 
of a country [14]. Education may have a central role to play as a more sustainable way of development. Furtado (1977) states that development, which has the meaning of 'change' in society, seems to be closely connected to economic change and particularly connected to economic growth. According to him, it would be impossible to improve one's life without considering the economic factors because the latter is related to comfortable living [4].

This article explores various approaches to developing and implementing economics curricula, weighs their benefits and drawbacks, and ends with a suggestion for blending the alternatives so as to optimize the benefits. Prior to the development of a curriculum rationale, however, the educator must ask a question seldom raised with the other social sciences: What kind of economics should be taught? Positive Versus Normative Economics The positive versus normative distinction in economics is particularly important in economic education. In the words of one Nobel laureate in economics: Positive economics is in principle independent of any particular ethical position or normative judgments [8]. As [John Neville] Keynes says, it deals with "what is," not with "what ought to be." Its task is to provide a system of generalizations that can be used to make correct predictions about the consequences of any change in circumstances. Its performance is to be judged by the precision, scope, and conformity with experience of the predictions it yields. In short, positive economics is, or can be, an "objective" science, in precisely the same sense as any of the physical sciences. Positive economics means a set of testable propositions, hypotheses, or predictive statements about economic phenomena or economic behavior (or what are generally referred to as scientific propositions) [3]. They take the form of statements such as, "If A occurs, then B will follow." Such statements can be tested and disproved by confrontation with real world data. In short, they are statements (or laws) that can be dis-verified.

By contrast, normative economic propositions are not testable hypotheses or verifiable propositions. Normative statements are of the sort, "Situation X ought to be the way the world works" or "The U.S. Congress ought to enact this law." In sum, normative propositions are statements of opinion, values, or preferences. They are a scientific in that they cannot be tested with data to disprove them. Positive economics is the heart of economics as a social science and as a discipline that is relatively free of value biases or special-interest orientation. Teachers need to be trained in positive economics and they need to convey to their students the distinction between positive and normative economics. With solid grounding in positive economic analysis, teachers are more likely to detect propaganda or special interest indoctrination in outside materials they are given to examine or in textbooks being considered for adoption. Having addressed the question of what kind of economics to teach, the following sections turn to a discussion of some alternative approaches to economic education through the school curriculum. Each of the curricular approaches identified has benefits and each has drawbacks. The choice of curricular approach should be made with full knowledge of these benefits and drawbacks.

\section{Teacher-Developed Versus Informal Curriculum}

Because informal curriculum in a district is usually teacher centered, accomplishing this type of curriculum change requires a "shotgun" approach. Individual teachers develop individualized teaching strategies (within broader curriculum guidelines specified by the state, the school district, or the specific school) and are less likely to be influenced by what other teachers in the school or district are doing in a curricular sense. Informal curriculum may be introduced by a teacher because of new materials he or she has "found" (such as the Trade-offs, 1978 [15], or the Give \& Take, 1982 [5], video series). It may also be stimulated by a course the teacher has taken and enjoyed, or by personal interests. In other words, informal curriculum is that curriculum developed by individual teachers for their individual classrooms. Benefits Through economics education classes, in service programs, and innovative new materials, classroom teachers can be introduced to economics content and methods for teaching it in their classrooms. Once these teachers are shown that economics is interesting, is not intimidating, and is of importance to their students, they will then be more likely to infuse economics into their informal classroom curriculum. They may even become enthusiastic supporters of economics in their classrooms. However, trained and interested teachers are a prerequisite for a successful informal curriculum. In general, economics has not been a subject commonly recognized by K-12 teachers as an essential part of the curriculum. Economics is seldom required for any teaching certificate other than business education, home economics, or some social studies majors. Therefore, the average elementary teacher is untrained in economics and is most likely to feel much more comfortable with history, math, or even geography, than with economics.

\subsection{Drawbacks}

Although the informal approach has potential for success, it has several significant drawbacks. One major drawback is that economics will be taught only so long as the individual teacher remains interested in teaching economics and remains in the classroom. If the teacher stops teaching that class or is introduced to another subject of interest (e.g., chemical abuse, sex education, or any other "new wave" topic), there is no assurance that economics will continue to be taught. To eliminate this transitory effect, the teacher must be continually reminded of the need to teach economics, stimulated by additional new teaching materials, and encouraged to continue economics among all the competing educational needs. In addition, one may find that several teachers, at differing grade levels or disciplines, are stimulated by the same materials or ideas. This could be beneficial if teachers link their teachings together into a 
comprehensive and thorough study of the subject matter. However, it is also possible that common subject interest among several teachers may have unfortunate side effects. Independent decisions by several teachers that a particular video series fits into their classroom curriculum could (and often does) result in students seeing the same video series at three grade levels (e.g., grades 4, 6, and 7). Since informal curriculum rarely involves teachers in intergrade or interdisciplinary coordination and curriculum development, students may experience "diminishing returns" from an excellent teaching resource that ends up being used repeatedly at different grade levels. The grades 4-8 economic video series, Trade-offs, is excellent the first time the films or tapes are viewed. They may even provide reinforcement the second time they are seen. However, by the third viewing students are likely to be completely turned off by the series and by the economics the shows teach. Another shortcoming of the informal curriculum approach has to do with the subject's priority ranking in the district's overall curriculum plan. Recently, in a qualitative evaluation of an intensive DEEP curriculum [7], found that when teachers were asked to identify district priorities for curriculum, they responded according to what was included in the formal testing/evaluation process. Thus, even though the district may state that economic education is a district priority, if economics is not included in the formal student evaluation process, teachers will assume that their highest priority should be those subjects over which the students will be tested. Since informal curriculum is teacher-specific, it is not possible to formalize economics introduced this way into the school's priority scheme through the student testing program [9]. Also, without a formal curriculum, it is nearly impossible to build student knowledge in economics from grade level to grade level. District-Developed Formal Curriculum Many school districts around the country are required by their state departments of education to submit formal district-wide curriculum plans for various subjects and to review and/or revise these plans periodically. The process to be used in the development of these curricula differs from district to district and even between grades in a given district. In some cases, the district may appoint a committee composed of teachers from a variety of school buildings in a given grade level (e.g., third grade). In other cases, the district may appoint a committee composed of different grade-level teachers in one discipline (e.g., social studies). At the high school level, a curriculum committee may be composed of the one person teaching the course or of several people within a subject area department. Whatever the process, a formal curriculum is the result.

\subsection{Benefits}

Although actual learning takes place because of the teaching of informal curriculum (what happens when the teacher closes the classroom door), formal district-developed curriculum provides the skeleton upon which activities, readings, media, etc., can be placed. It can also be seen as a road map that conceptualizes where the student begins, what the student should know at the end, and how this learning should develop. Since students will have a minimum of 12 teachers and may have as many as 40 or more teachers before graduation from high school, districts need to determine basic educational outcomes and paths by which the students can reach these outcomes. Through formal curriculum, the emphasis on economics is less transitory. When left to teacher-developed informal curriculum, economics may become only a series of unrelated units, activities, films, or projects. The continuity provided by the formal district-wide curriculum enables students to develop economic decision making skills and to internalize those skills in their lifestyles. Without this skeleton of formal economics curriculum throughout the students' educational experience, economics never becomes the dynamic, interactional activity that they will use the rest of their lives. A side benefit of the formal curriculum is that interaction between teachers of different grade levels or disciplines increases. Problems such as the use of the same film or activity at several grade levels are encountered and resolved through the process of curriculum articulation across grade levels and departmental lines. By making economics a part of the formal district-wide curriculum, the teaching of this important knowledge and these crucial skills can be insured. Education tends to be cyclical. Emerging research or materials often direct educational interests into new directions almost yearly. If economics is included as a part of the formal curriculum, it is then protected against the changing interests of individual teachers. Additionally, if economics is included as a part of the district's student evaluation/testing program, it is accorded a higher priority in the system's activities. By including economics in the students' competency tests, the district is stating that economic understandings are essential to the students' progression through the system.

\subsection{Drawbacks}

A problem with formal curriculum is the uncertainty of how it will be interpreted by the individual teacher. If the teacher is not trained in or prepared to teach a subject, it will not be taught or taught well regardless of formal curriculum requirements. This is especially critical with economics. Very few teachers have had courses in economics. Even fewer teachers have had enough economics courses to actually grasp the discipline and apply its understandings to new or unique situations or issues. Thus, unless adequate training is provided, integrating economics into the formal curriculum does not assure that economics will be taught or that it will be taught as positive economic analysis instead of normative indoctrination. "Outside" Curriculum.

Curriculum can also be developed from a variety of outside sources and then inserted into the existing curriculum. The most common source is the textbook. Studies have shown repeatedly and consistently that the majority of subject content taught in most classrooms is determined by text-book content. However, a multitude of additional curricular materials dealing with a variety of topics or disciplines have been developed by individuals, 
organizations, governmental agencies, and business firms. Economics certainly has a plethora of these available, some of which are very good and some of which are very bad. In addition, economics has varying state curriculum guidelines and attempts to develop scope and sequence guidelines for economics are under way at the national, state, and local levels. All of these outside curricula have varying benefits and drawbacks.

\subsection{Benefits}

If a teacher-developed curriculum reflects the wisdom of one teacher and the district-developed curriculum reflects the wisdom of several teachers, the outside curriculum may reflect the abilities and/ or thoughts of one or more recognized experts on the subject. This is not to say that this is always the case. However, outside curriculum can utilize individuals with special expertise in economics education or in curriculum development. Thus, the result may be more professional than that of the local district.

\subsection{Drawbacks}

If, however, the curriculum reflects a particular point of view or attempts to indoctrinate students rather than introduce them to positive economic analysis, the negative aspects outweigh the benefits. Again, the best defense against "bad" outside curriculum is trained and economically literate teachers and curriculum administrators within the school. Teachers in general are likely to be adept at identifying outside curricula that are deficient in terms of their educational merit or their "teach-ability" in the classroom, but they are less likely to be able to detect flawed subjectmatter content, unless they themselves have acquired a strong economics educational background. Once past the examination phase of outside curriculum, the schools must cope with the problem of adaptation. In other words, even the best of outside curricula must be adapted to the specific environment of the local schools implementing the curriculum. With over 16,000 individual school districts, education in the United States has been called "a cottage industry." No two districts are exactly alike in any of their significant dimensions. In particular, the students and the teaching staffs differ substantially across district lines. How can anyone expect a national ("cookbook") curriculum to work equally well (if at all) across these school lines without significant adaptation and modification to fit the peculiarities of individual school districts? In the absence of built-in possibilities for local adaptation, cookbook curricula are doomed to failure in the schools. A related problem is that cookbook curricula are often touted as being "teacher-proof" or "teacher-independent." Claims such as, "This curriculum is so good that teachers don't even have to know anything about the subject," ought to be flatly rejected. There simply is no such thing as a teacher-proof curriculum that works! Educators know this instinctively, and the point has been proven by ample evidence from prestigious national curriculum projects such as those of the National Science
Foundation, let alone the material from Junior Achievement and the U.S. Chamber of Commerce. Simply put, nothing can substitute for teachers adequately trained in the subject they are to teach. Although the situation is no different when the subject is economics, teachers do not have to be professional economists to teach the field. Rather, they need good pre service and/or in service training in economic education courses delivered by competent economic education professionals. The minimum "dosage" of economics training should be one or two semester-length courses in the subject, while the optimal amount of economics training is considerably more, and depends on the grade levels taught and the degree of specialization the teacher must practice. An elementary teacher might be well served with 2-5 courses in economics, while a high school economics teacher is likely to need from 5 to 10 courses in the field (acquired, in either case, over a number of years).

In any event, some formal training of teachers in economics must occur if an adequate economics curriculum is to be implemented in a school system or building. Numerous sources of such training are readily available to virtually all teachers in the United States through the colleges and universities affiliated with the Joint Council on Economic Education. This national network of 50 state councils and 270 university-based centers for economic education offers teacher-focused courses and workshops in economic education, curriculum development assistance to teachers and school districts, economics materials distribution and development, and program evaluation assistance, usually at moderate cost. In short, lack of trained teachers is no excuse for failure to implement a sound economic education component in the schools, as external assistance is readily available to virtually all school systems and teachers.

\section{The Infusion Approach Versus the Separate Course}

Another economics curriculum decision often confronting a school system is whether or not to use an infusion approach to teaching economics. The major alternative to curriculum infusion is to focus on economics in one or two specific courses within the overall curriculum. Benefits of Infusion Perhaps the major advantage of the infusion approach to economic education is that the subject is blended into the existing curriculum (usually within the social studies or business education components) without the addition of a new, separate course in economics. Another benefit of the infusion approach is that all or most teachers in a school or school system are potential teachers of economics, either directly or through reinforcement activities. Moreover, student knowledge of economics can support greater understanding of other subjects. For example, students can interpret and analyze history better with greater understanding of economics. A good infusion program may yield high dividends, particularly in an elementary school 
set-ting by focusing the attention of the entire faculty on economics as a significant curriculum component.

\subsection{Drawbacks of Infusion}

The infusion approach to economic education can be a sound and low-cost alternative to the use of a separate course or courses in the subject, but it is not without problems, particularly at the secondary level. Recent evidence from the national norming of the Test of Economic Literacy [11, 12], strongly suggests that students who receive their economic education through infusion in social studies courses without a specific economics component learn significantly less economics than do students who take a separate course in the subject [13]. Moreover, students taught via the infusion approach have less favorable attitudes toward economics as a subject and are less sophisticated in their attitudes toward economic problems or issues.

\subsection{Benefits of the Separate Course}

By focusing attention on one or two specific courses in the K-12 curriculum, a school system might achieve the highest returns in student knowledge of economics and favorable attitude formation at the lowest possible cost. In this way, only a small number of teachers need to be trained and updated in economics, and textbooks and other student materials may be selected with the greatest efficiency. The school may minimize costs while it maximizes output in terms of student learning and attitudes, at least for those students who take the separate course.

\subsection{Drawbacks of the Separate Course}

The separate course approach to economic education shows strong evidence of success, but that success will be limited to those students who actually complete such a course or courses. Unless the economics course is a graduation requirement (of either the school system or the state), large numbers of students are likely to graduate from high school with no economics training at all. If a separate economics course is mandated for all students in a school district or in the state, the cost advantage of the separate course may slip away. In this case, a larger number of teachers must be well trained in economic education, and the opportunity cost of another required course in the curriculum must be faced. Moreover, economics is a subject that lends itself well to a developmental approach, where the subject is best learned over time and across many different grade levels. As students grow and mature, they acquire much economic information from non-school sources; some of this "street economics" is correct, some of it is not. If formal economic education is ignored until the senior year of high school, a tremendous amount of time will be lost in correcting previously learned errors and prejudices. Finally, significant numbers of students drop out of school well before the senior year of high school, and thus would be totally deprived of any worthwhile economic education. School dropouts are perhaps those most in need of this very training.

\section{A Synthetic Approach}

To conclude this examination of economics in the curriculum, it may be permitted that we offer at least one normative proposition: The best approach to economics in the curriculum is a blending or synthesis of the alternatives, rather than opting for a pure this-or-that choice. For example, teachers might be encouraged to maximize the advantages of the teacher-developed, informal curriculum in economics through the use of new and innovative materials and strategies for teaching economics in their individual classrooms, and through the pursuit of additional teacher training in economic education courses and workshops. At the same time, the district can ensure adequate coverage of economics through a developmental process in grades $\mathrm{K}-12$ by fostering a district-wide economics curriculum. Such a district-developed curriculum can call upon outside experts to assist teachers and curriculum developers as they perfect a unique curriculum over which they feel ownership. By working with outside resources and carefully developed national curriculum models or guidelines, the local schools can adapt the best of the outside to their inside needs. Truly excellent economic education also involves the blending of both infusion and separate course approaches. Infusion of economic education throughout the curriculum (particularly the K-8 levels) will enable schools to maximize returns from the developmental approach to economics learning at relatively low cost. Yet more intensive and specialized economics instruction can be effected in a separate course or courses at the secondary level, ending with a one-or-two semester "capstone" course at grade 11 or 12 . This blended approach to the economics curriculum is likely to yield the highest levels of economic knowledge for students at all age and ability levels, and minimize the problem of students "escaping" without any worthwhile economic education. At the same time, the schools can have confidence in the quality of economics taught and can keep the total costs of curriculum implementation within reasonable limits.

\section{References}

[1] Toghyani Khorasgani A. and Rahmani J. (2019). Curriculum Planning based on Economic Knowledge in Some Developed Countries. IJRDO - Journal of Educational Research (ISSN: 2456-2947), 4 (5), 13-27. Retrieved from https://www.ijrdo.org/index.php/er/article/view/2836

[2] Ebersole, B. P. (1980). Foreword. In A. W. Forshay (Ed.), Considered action for curriculum improvement (p. iv). Washington, DC: Association for Supervision and Curriculum Development.

[3] Friedman, M. (1953). The methodology of positive economics. In Essays in positive economics (pp. 3-43). Chicago, IL: The University of Chicago Press.

[4] Furtado, C. (1977). Development. International Social Science Journal, 24 (4), 628e650. 
[5] Give \& take. (1982). Bloomington, IN: Agency for Instructional Television; and New York: Joint Council on Economic Education.

[6] Macdonald, J. B. (1977). Values bases and issues for curriculum. In A. Molnar \& J. A. Zahorik (Eds.), Curriculum theory (pp. 10-21). Washington, DC: Association for Supervision and Curriculum Development.

[7] Morley, S. C. (1986). Implementation of the economics curriculum, kindergarten through eighth grade, East Cleveland School District: Case study. Unpublished manuscript, John Carroll University.

[8] Nabers, L. (1966). The positive and genetic approaches. In S. R. Krupp (Ed.), The structure of economic science: Essays on methodology (pp. 68-82). Englewood Cliffs, NJ: PrenticeHall.

[9] Nagel, E. (1961). The structure of science: Problems in the logic of scientific explanation. New York: Harcourt, Brace \& World.
[10] Parkay, F. W. and G. Hass. 2000. Curriculum planning: A contemporary approach, 7th edition. Boston: Allyn and Bacon.

[11] Soper, J. C., \& Brenneke, J. S. (1981, Summer). The test of economic literacy and an evaluation of the DEEP system. The Journal of Economic Education, 12, 1-14.

[12] Soper, J. C., \& Walstad, W. B. (1986a). The test of economic literacy (2nd. ed., Forms A and B). New York: Joint Council on Economic Education.

[13] Soper, J. C., \& Walstad, W. B. (1986b, December). What is high school economics? Part II: National posttest results. Paper presented at the Allied Social Science Association annual meetings, New Orleans, LA.

[14] Sumner, A., \& Tribe, M. (2010). International development studies: Theories and methods in research and practice. London, UK: SAGE.

[15] Trade-offs. (1978). Bloomington, IN: Agency for Instructional Television; and New York: Joint Council on Economic Education. 